\title{
Effectiveness of Dexmedetomidine as a Coadyuvant in Analgesia and Epidural Anesthesia in Hysterectomies
}

\author{
Jaquelina Martínez Sotomayor Melero, Jesús Ricardo Canseco Nieto*, Hilda Alicia Llanes Garza and \\ Nora Cecilia Cruz Rodríguez \\ Department of Anesthesiology, Autonomous University of Nuevo León, USA
}

*Corresponding author: Jesús Ricardo Canseco Nieto, Department of Anesthesiology, University Hospital Dr José Eleuterio González, Autonomous University of Nuevo León, Monterrey, USA.

Received Date: January 08, 2020

Published Date: January 21, 2020

\section{Abstract}

Introduction: Dexmedetomidine is an alpha-2 agonist that has sympatholytic, sedative, analgesic and sedative properties at the central level, which can be used as an adjuvant to anesthetics and analgesics at epidural and peripheral levels, prolonging and accelerating their action due to their properties Fat-soluble and high affinity for adrenoceptors and thus reduce their side effects. Add adjuvants to local anesthetics for better and more rapid testing at the beginning of the block, prolonging their duration, action and postoperative analgesia with lower doses of local anesthetics. Adjuvants such as opioids are used for this activity coupled with its side effects such as pruritus, urinary retention, nausea or vomiting.

Material and Methods: A prospective, comparative, randomized, blind, longitudinal study was conducted. 24 patients scheduled for elective hysterectomy were invited to participate in the study, of which 2 were eliminated due to a change in anesthetic technique.

Results: When assessing the time in which the patients reached a maximum sensory level, they found that patients in the dexmedetomidine group required a longer time (11.8 \pm 4.6 vs. $6.3 \pm 2.4$ minutes, $\mathrm{P}=0.002)$, however, we found no differences in the dorsal level of maximum sensory level $(\mathrm{P}=0.23)$, in addition, the motor level time was greater in dexmedetomidine patients $(17.2 \pm 7.2 \mathrm{vs.} 9 \pm 2.6, \mathrm{P}=0.002)$.

Conclusions: Dexmedetomidine is a useful medication for analgesia and anesthesia in elective patients with hysterectomy compared to fentanyl, and the safety profile is similar in both anesthetics. In addition, we found that patients with dexmedetomidine take a longer time to reach their maximum sensory and motor level, so that they could gently prolong the surgeries.

Keywords: Dexmedetomidine; Adjuvant; Epidural anesthesia; Hysterectomy

\section{Introduction}

Dexmedetomidine is an alpha-2 agonist that has sympatholytic, sedative, analgesic properties at the central level, which can be used as an adjuvant for anesthetics and analgesics at the central and peripheral levels, prolonging and accelerating their action due to their fat-soluble properties and high affinity for adrenoceptors and thus reduce their side effects [1]. Its properties make it a suitable drug for sedation and analgesia during the entire perioperative period. Its applications as an analgesic, auxiliary anesthetic for general and regional anesthesia and postoperative sedative are similar to benzodiazepines [2].

Dexmedetomidine was approved in the United States by the Food and Drug Administration (FDA) in 1999 for use in humans as a short-term medication ( $<24$ hours) for sedation / analgesia in the intensive care unit [2]. Add adjuvants to local anesthetics that have been tested better and faster at the beginning of the block, prolonging their duration, action and postoperative analgesia with lower doses of local anesthetics. Adjuvants such as opioids are used for these activities together with their side effects such as pruritus, urinary retention, nausea or vomiting [3].

New adjuvants have been considered as dexmedetomidine in reduced doses combined with local anesthetics to improve the quality of intraoperative and postoperative anesthesia, help early ambulation and motor block recovery, and reduce the incidence of associated side effects [4]. Hysterectomy is one of the most frequent surgical procedures performed in the United States. During 2000-2004 approximately 3.1 million hysterectomies were performed, (approximately 600 thousand per year). Worldwide, the hysterectomy defined as surgical removal of the uterus is also 
the most frequently performed gynecological surgery, with millions of procedures performed annually worldwide. Only in our hospital about 1-2 daily hysterectomies are performed [5].

The addition of adjuvants such as opioids or $\alpha-2$ agonist provides a dose-saving effect of local anesthetics and would accelerate the onset of sensory blockage of epidural anesthesia and decrease the effective dose of local anesthetic. Motor blockage tends to be denser with dexmetomidine [6].

The mechanism of analgesic action is unknown although it seems to produce endogenous modulation due to its effect on the receptors located at the level of the spinal cord and brain spine and for its action on substance P [7], it is produced by activation of Spinal cholinergic neurons that release acetylcholine and nitric oxide (NO), dexmedetomidine shows greater affinity in the spinal cord membranes than in the brain, it is 5 times more effective epidural than systemic [8].

Its sedative effect is mediated by the inhibition of the locus coeruleus, (predominant noradrenergic nucleus), located in the brain stem inhibiting nocioceptive neurotransmission through the posterior horn of the spinal cord [3], also acting on the presynaptic membrane, inhibiting the Norepinephrine release, which in turn induces hyperpolarization and inhibits pain signals in the brain. Get effective sedation with ease of waking, similar to physiological sleep (non-REM phase) [2].

Dexmedetomidine due to its liposolubility properties and high affinity for adrenoceptors, provides some beneficial effects when administered epidurally: sedation, analgesia, anxiolytic and sympatholytic effects associated with hemodynamic stability [4].

Shaikh mentions that the epidural administration of $15 \mathrm{ml}$ of $0.5 \%$ isobaric bupivacaine with $1 \mu \mathrm{g} / \mathrm{kg}$ of dexmedetomidine provided superior early onset analgesia, superior intraoperative analgesia, stable cardiorespiratory parameters, prolonged postoperative analgesia and greater patient comfort, in comparison with $15 \mathrm{ml}$ of $0.5 \%$ isobaric bupivacaine with $2 \mu \mathrm{g} / \mathrm{kg}$ of clonidine in patients undergoing orthopedic surgery of the lower limb [9-11].

The objective of this study was to compare the use of dexmedetomidine as an adjuvant in epidural block vs fentanyl as an adjuvant in patients scheduled for elective hysterectomies.

\section{Materials and Methods}

A case-control study was carried out with an ambispective, longitudinal, observational, comparative, analytical design, which was carried out with prior authorization of the ethics committee and under the signature of an informed consent, electively programmed hysterectomy patients were identified and that they met the inclusion criteria and was randomly selected according to the air currency method. The study included 24 patients scheduled for an elective hysterectomy to participate in the study, of which 2 were eliminated due to a change in anesthetic technique. Patients younger than 18 years or older than 60 , with a history of allergies to the drugs to be used, patients with hemodynamic instability or alterations in the state of consciousness, patients who were under opioid, antidepressant or anxiolytic medication, patients with bleeding disorders, patients with BMI> 30, patients with hepatic or renal impairment or ASA II or IV patients were excluded.

In the patients included the main variables to be measured were postoperative VAS, opioid requirement and vital signs. Two study groups were formed in which group 1 will be the one receiving epidural dexmedetomidine $1 \mathrm{mcg} / \mathrm{kg}$, while group 2 has received epidural fentanyl $1 \mu \mathrm{g} / \mathrm{kg}$ and then the steps to follow were:

1. Vital signs (heart rate, blood pressure and respiratory rate) were recorded preoperatively and weighed and measured on a Roman scale, patients weighing in fractions of 0.5 down will be rounded to the lowest weight and 0.5 up took the weight rounded up

2. They were premedicated with midazolam at $0.04 \mathrm{mg} / \mathrm{kg}$, ranitidine $50 \mathrm{mg}$ and metoclopramide $50 \mathrm{mg}$

3. Type 1 monitoring was performed and facial mask was placed at 3 liters per min.

4. The patients were placed in a lateral decubitus position, $50 \mathrm{mcg}$ IV of fentanyl was passed and under aseptic precautions, L3-L4 intervertebral space was located and skin was infiltrated with simple lidocaine, an epidural block was made with TOUHY \# 18 needle using the technique of loss of resistance, the epidural space was located and the first dose of local anesthetic was administered plus catheter placement (in case of difficulty of 12-13).

5. According to the Bromage scale the dose will be detected according to the age of the patient to calculate the dose in $\mathrm{ml}$ per segment to reach a level of T4 (lidocaine with epinephrine) of the total anesthetic dose will be passed $10 \mathrm{ml}$ per needle and the rest per catheter)

6. Group 1 was added dexmedetomidine at a dose of $1 \mathrm{mcg}$ / kg per epidural catheter after placing the supine patient and group 2 was administered $1 \mathrm{mcg} / \mathrm{kg}$ of fentanyl per epidural catheter once the patient was placed in supine position

7. The registration of vital signs began. It was recorded: Maximum sensory level reached, time to reach the maximum sensory level, time to complete the motor block, time to segmental dermatome regression, the motor block was evaluated using the Bromage scale 1. Complete block (inability to move feet or knees) 2. Nearly complete block (able to move only feet) 3. Partial block (ability to move the knees incompletely) 4. Detectable weakness to hip flexion 5. No weakness of hip flexion detected supine (full knee flexion

8. Sedation was evaluated at 30-minute intervals intraoperatively from dose administration and at 1-hour intervals during the postoperative period using a subjective sedation scale (Grade 0 = awake, conscious, no sedation, slightly restless, Grade 1 = calm and cooperative; Grade 2 = awake in verbal command, Grade 3 = awake in soft tactile stimulation, Grade 4 = awake in vigorous shaking, Grade 5 = unconscious). 
9. At the end of surgery analgesia was given with paracetamol $1 \mathrm{gr} \mathrm{IV}$, ketorolac $30 \mathrm{mg}$ IV and morphine at $1 \mathrm{mg}$ per epidural catheter

10. First feeling of pain and need for rescue analgesia was recorded

11. In recovery, a patient was evaluated at admission, $15 \mathrm{~min}$, at the hour, two hours and 24 postoperative hours.

\section{Statistical Analysis}

Statistical analysis was performed using SPSS using mean and standard deviations, as well as student's and $\mathrm{x}^{2}$ tests for univariate / bivariate analysis).

\section{Results}

22 patients with a mean age of $41.4 \pm 7$ years were included. The clinical and preoperative data of the patients are described in Table 1.

Table 1: Clinical and anesthetic data of the patients.

\begin{tabular}{|c|c|c|c|c|}
\hline Variable & Global & Group 1 & Group 2 & P \\
\hline Age(years) & $41.4 \pm 7.0$ & $38.2 \pm 5.8$ & $46 \pm 6.2$ & 0.007 \\
\hline Weight(kg) & $74.5 \pm 16.7$ & $74.5 \pm 14.0$ & $74.6 \pm 20.9$ & 0.987 \\
\hline Size (m) & $1.58 \pm 0.06$ & $1.59 \pm 0.05$ & $1.56 \pm 0.07$ & 0.294 \\
\hline BMI (kg/m²) & $29.2 \pm 6.5$ & $28.8 \pm 6.0$ & $29.6 \pm 7.6$ & 0.79 \\
\hline $\begin{array}{c}\text { Preoperative } \\
\text { systolic blood } \\
\text { pressure } \\
\text { (mmH) }\end{array}$ & $126.7 \pm 19.7$ & $127.8 \pm 20.6$ & $125.1 \pm 19.4$ & 0.758 \\
\hline $\begin{array}{c}\text { Preoperative } \\
\text { diastolic blood } \\
\text { pressure } \\
\text { (mmHg) }\end{array}$ & $72.7 \pm 10.8$ & $73.1 \pm 11.8$ & $72.1 \pm 9.7$ & 0.83 \\
\hline $\begin{array}{c}\text { Preoperative } \\
\text { heart rate } \\
\text { (bpm) }\end{array}$ & $76 \pm 11$ & $76.5 \pm 12.6$ & $77.5 \pm 10.9$ & 0.847 \\
\hline $\begin{array}{c}\text { Preoperative } \\
\text { respiratory } \\
\text { rate (bpm) }\end{array}$ & $16 \pm 2$ & $16 \pm 2$ & $16 \pm 2$ & 0.511 \\
\hline
\end{tabular}

13 patients were included in the dexmedetomidine group and 9 in the fentanyl group. Basically, the only important difference detected between both groups was the age difference, where we detected that patients anesthetized with fentanyl were older (46 vs. 38.2 years, $P=0.007)$. In the rest of the characteristics of the patients, we found no significant differences. The mean dose of midazolam patients received was $2.7 \pm 0.9 \mathrm{mg}(11.8 \pm 4.6 \mathrm{mg}$ in the dexmedetomidine group vs. $6.3 \pm 2.4$ in the fentanyl group, $\mathrm{P}$ $=0.865$ ).

Table 2 describes some anesthetic variables considered during the evaluation of the patients. When assessing the time in which the patients reached a maximum sensory level, we found that patients in the dexmedetomidine group required a longer time $(11.8 \pm 4.6$ vs. $6.3 \pm 2.4$ mins, $\mathrm{P}=0.002$ ), however, we found no differences in the dorsal level of maximum sensory level $(\mathrm{P}=0.23)$. In addition, the motor level time was longer in dexmedetomidine patients $(17.2$ \pm 7.2 vs. $9 \pm 2.6, \mathrm{P}=0.002$ ). Regarding the duration of surgery and anesthesia, we found no significant differences ( $P>0.05)$. Overall, a second dose of anesthesia was required in $16(72.7 \%)$ of the patients, with no predominance in any group $(\mathrm{P}=0.467)$; The time between the first and second doses was $97.3 \pm 22.3$ minutes. The reasons for the indication of a second dose were mainly pain in 10 (45.5\%), hourly indication in $5(22.7 \%)$ and prolongation of surgery in 1 (4.5\%). Despite not finding significant differences in the reasons for a new indication of blocking dose, we found that in $83.3 \%$ of patients with fentanyl they needed a new dose due to pain complaints. In the dexmedetomidine group, the main reason was also a complaint of pain in $50 \%$, and secondly the hourly indication in $40 \%$. Three adverse events were reported in the study, of which two events were nausea and one hypotension in the dexmedetomidine group. A sedative dose was given in $53.8 \%$ of the patients with dexmedetomidine and $33.3 \%$ in the fentanyl group. In the dexmedetomidine group, the main sedative drug used was Propofol in $57.2 \%$, mainly indicated by concern in $80 \%$, and in the fentanyl group it was midazolam in $100 \%$, mainly to decrease the degree of anxiety in $66.6 \%$ of patients.

Table 2: Clinical and transoperative anesthetic considerations.

\begin{tabular}{|c|c|c|c|c|}
\hline Variable & Global & Group 1 & Group 2 & $\mathbf{P}$ \\
\hline $\begin{array}{l}\text { Midazolam } \\
\text { dose(mg) }\end{array}$ & $2.7 \pm 0.9$ & $2.6 \pm 0.8$ & $2.7 \pm 1.1$ & 0.865 \\
\hline $\begin{array}{c}\text { Sensory } \\
\text { level(min) }\end{array}$ & $9.5 \pm 4.7$ & $11.8 \pm 4.6$ & $6.3 \pm 2.4$ & 0.002 \\
\hline Sensory level & & & & 0.32 \\
\hline $\mathrm{T} 4$ & $16(72.7 \%)$ & $8(61.5 \%)$ & $8(88.9 \%)$ & \\
\hline $\mathrm{T} 5$ & $2(9 \%)$ & $2(15.4 \%)$ & $0(0 \%)$ & \\
\hline T6 & $4(18.3 \%)$ & $3(23.1 \%)$ & $1(11.1 \%)$ & \\
\hline $\begin{array}{l}\text { Engine level } \\
\text { time(min) }\end{array}$ & $13.8 \pm 7.0$ & $17.2 \pm 7.2$ & $9 \pm 2.6$ & 0.002 \\
\hline $\begin{array}{c}\text { Duration of } \\
\text { surgery(min) }\end{array}$ & $130.0 \pm 39.6$ & $138.6 \pm 37.7$ & $117.6 \pm 41.2$ & 0.23 \\
\hline $\begin{array}{c}\text { Duration of } \\
\text { anesthesia(min) }\end{array}$ & $168.9 \pm 39.2$ & $179.3 \pm 33.5$ & $153.8 \pm 43.8$ & 0.137 \\
\hline $\begin{array}{l}\text { Second dose of } \\
\text { anesthesia }\end{array}$ & $16(72.7 \%)$ & $10(76.9 \%)$ & $6(66.7 \%)$ & 0.467 \\
\hline $\begin{array}{c}\text { Time between } \\
\text { doses(min) }\end{array}$ & $97.3 \pm 22.3$ & $97.5 \pm 28.1$ & $97.1 \pm 8.9$ & 0.973 \\
\hline \multicolumn{5}{|c|}{ Reasons For Second Anesthesia } \\
\hline Pain & $10(45.5 \%)$ & $5(50 \%)$ & $5(83.3 \%)$ & \\
\hline $\begin{array}{c}\text { Surgery } \\
\text { extension }\end{array}$ & $1(4.5 \%)$ & $1(10 \%)$ & $0(0 \%)$ & \\
\hline Schedule & $5(22.7 \%)$ & $4(40 \%)$ & $1(16.7 \%)$ & \\
\hline Adverse effects & $2(9 \%)$ & $2(15.3 \%)$ & $0(0 \%)$ & \\
\hline Nausea & $2(100 \%)$ & $2(100 \%)$ & $0(0 \%)$ & \\
\hline Hypotension & $1(50 \%)$ & $1(50 \%)$ & $0(0 \%)$ & \\
\hline Sedation & $10(50 \%)$ & $7(53.8 \%)$ & $3(33.3 \%)$ & 0.415 \\
\hline Midazolam & $6(60 \%)$ & $3(42.8 \%)$ & $3(100 \%)$ & \\
\hline Propofol & $4(40 \%)$ & $4(57.2 \%)$ & $0(0 \%)$ & \\
\hline \multicolumn{5}{|c|}{ Reason } \\
\hline Anxiety & $2(20 \%)$ & $1(14.2 \%)$ & $2(66.6 \%)$ & \\
\hline Restlessness & $8(80 \%)$ & $6(85.8 \%)$ & $1(33.3 \%)$ & \\
\hline
\end{tabular}

At the postoperative period, the recovery time was 237.6 vs. 186.1 minutes When adjusting the recovery time to only patients 
who received a single dose of anesthetic, we found that patients in the dexmedetomidine group required a shorter recovery time (141.6 vs. 241.6 minutes, $\mathrm{P}=0.036$ ). The use of a rescue drug for pain was required for a single patient in the dexmedetomidine group, throughout the study. He was instructed to use ketorolac. Regarding the degree of satisfaction, we found no significant differences $(\mathrm{P}=0.415)$ (Table 3).

Table 3: Postoperative anesthetic and analgesic considerations.

\begin{tabular}{|c|c|c|c|c|}
\hline Variable & Global & Group 1 & Group 2 & P \\
\hline $\begin{array}{c}\text { Minutes in } \\
\text { recovery }\end{array}$ & $216.5 \pm 95.9$ & $237.6 \pm 110.5$ & $186.1 \pm 63.7$ & 0.223 \\
\hline $\begin{array}{c}\text { Minutes in } \\
\text { recovery } \\
\text { (patients with } \\
\text { one dose) }\end{array}$ & $191.6 \pm 65.1$ & $141.6 \pm 35.4$ & $241.6 \pm 43.1$ & 0.036 \\
\hline $\begin{array}{c}\text { Rescue use for } \\
\text { pain }\end{array}$ & $1(4.5 \%)$ & $1(7.7 \%)$ & $0(0 \%)$ & $>0.999$ \\
\hline \begin{tabular}{c} 
Ketorolac \\
\hline $\begin{array}{c}\text { Satisfaction } \\
\text { level }\end{array}$
\end{tabular} & $1(4.5 \%)$ & $1(100 \%)$ & $0(0 \%)$ & 0.415 \\
\hline 1 & $12(54.5 \%)$ & $6(46.2 \%)$ & $6(66.7 \%)$ & \\
\hline 2 & $10(45.5 \%)$ & $7(53.8 \%)$ & $3(33.3 \%)$ & \\
\hline
\end{tabular}

Table 4 reported Ramsay scale scores during surgery. We found a higher level of sedation (higher Ramsay score) at 60 and 90 minutes $(\mathrm{P}<0.05)$. Upon recovery, we found no differences in scores (Table 5).

Table 4: Ramsay scale assessment during the transoperative period..

\begin{tabular}{|c|c|c|c|}
\hline Ramsay Scale & Group 1 & Group 2 & P \\
\hline Initial & $2(2-3)$ & $2(2-3)$ & 0.556 \\
\hline 30 mins & $3(3-4)$ & $3(2-3)$ & 0.144 \\
\hline 60 mins & $4(3-4)$ & $3(2.5-3)$ & 0.011 \\
\hline 90 mins & $4(3-4)$ & $3(2-3)$ & 0.016 \\
\hline 120 mins & $3(2.5-4)$ & $3(2-3)$ & 0.241 \\
\hline End of surgery & $3(2-3)$ & $2(2-2.5)$ & 0.186 \\
\hline
\end{tabular}

Table 5: Assessment by Ramsay scale during the postoperative period.

\begin{tabular}{|c|c|c|c|}
\hline Ramsey Scale & Group 1 & Group 2 & P \\
\hline Basal & $3(2-3)$ & $2(2-3)$ & 0.209 \\
\hline 15 mins & $3(2-3)$ & $3(2-3)$ & $>0.999$ \\
\hline 30 mins & $2(2-2.5)$ & $2(2-3)$ & 0.357 \\
\hline 60 mins & $2(2-2)$ & $2(2-2.5)$ & 0.393 \\
\hline 120 mins & $2(2-2.75)$ & $2(2-3)$ & 0.754 \\
\hline End of surgery & $3(2-3)$ & $2(2-2.5)$ & 0.186 \\
\hline
\end{tabular}

Table 6: Global and transoperative incidence of hypotension and bradycardia.

\begin{tabular}{|c|c|c|c|c|c|c|}
\hline \multirow{2}{*}{ Global } & \multicolumn{3}{|c|}{ Bradycardia Incidence } & \multicolumn{3}{c|}{ Bradycardia Incidence } \\
\cline { 2 - 7 } & Group 1 & Group 2 & P & Group 1 & Group 2 & P \\
\cline { 2 - 7 } & $\mathbf{1 0}(\mathbf{7 6 . 9} \%)$ & $\mathbf{8 ( 8 8 . 9 \% )}$ & $\mathbf{0 . 6 1 6}$ & $\mathbf{6 ( 4 6 . 2 \% )}$ & $\mathbf{3 ( 3 3 . 3 \% )}$ & $\mathbf{0 . 6 7 4}$ \\
\hline 0 & $1(7.7 \%)$ & $2(22.2 \%)$ & 0.544 & $0(0 \%)$ & $0(0 \%)$ & $/ /$ \\
\hline 15 & $4(30.8 \%)$ & $6(66.7 \%)$ & 0.192 & $2(15.4 \%)$ & $1(11.1 \%)$ & 0.999 \\
\hline 30 & $4(30.8 \%)$ & $4(44.4 \%)$ & 0.662 & $3(23.1 \%)$ & $0(0 \%)$ & 0.24 \\
\hline 45 & $6(46.2 \%)$ & $7(77.8 \%)$ & 0.203 & $3(23.1 \%)$ & $1(11.1 \%)$ & 0.616 \\
\hline 60 & $4(30.8 \%)$ & $6(66.7 \%)$ & 0.192 & $4(30.8 \%)$ & $2(22.2 \%)$ & $>0.999$ \\
\hline 75 & $3(23.1 \%)$ & $7(77.8 \%)$ & 0.027 & $5(38.5 \%)$ & $2(22.2 \%)$ & 0.648 \\
\hline 90 & $6(46.2 \%)$ & $1(11.1 \%)$ & 0.174 & $4(30.8 \%)$ & $0(0 \%)$ & 0.131 \\
\hline 105 & $8(61.5 \%)$ & $4(44.4 \%)$ & 0.673 & $4(30.8 \%)$ & $0(0 \%)$ & 0.131 \\
\hline
\end{tabular}

We found no differences in the incidence of hypotension (defined by> 20\% decrease in blood pressure in systole and / or diastole with respect to baseline) or bradycardia (heart rate $<60$ beats per minute). The highest incidence of hypotension occurred at 45 minutes, and bradycardia at 75 minutes $(\mathrm{P}>0.05)$ (Table 6).

\section{Discussion}

In our study we found that, tightly, patients with dexmedetomidine require less recovery time after surgery, however, it takes longer to achieve maximum sensory and motor level. In addition, the use of dexmedetomidine does not prolong surgical or anesthetic time $[12,13]$.

Dexmedetomidine is a potent $\alpha 2$-adrenergic selective agonist that is used for its anxiolytic, sedative and analgesic properties, which was initially approved in intravenous administration for sedation in adult patients with mechanical ventilation in the intensive care unit for up to 24 hours, and subsequently its use as a sedative was allowed in non-intubated patients before and / or during other procedures, including surgical procedures [14-16]. In our study we found that patients with dexmedetomidine showed a better level of sedation and a lower amount of intravenous intravenous sedative requirements. The mechanism by which $\alpha 2$ adrenergic agonists prolong sensory and motor blockade is not well understood, but it is known that they act by binding to presynaptic $\mathrm{C}$ fibers and postsynaptic dorsal horn neurons. The analgesic action is through the decrease of the secretion of transmitters of the $\mathrm{C}$ fibers and the hyperpolarization of the postsynaptic neurons of the dorsal horn [17]. It has also been found that $\alpha 2$ receptor agonists have nociceptive action for both somatic and visceral pain [18]. On the other hand, fentanyl is a lipophilic opioid agonist of the $\mu$ receptor that exerts its effect by binding to opioid receptors of the spinal cord dorsal horn and could have supraspinal action and expansion [19]. Fukushima et al used $2 \mu \mathrm{g} / \mathrm{kg}$ of epidural dexmedetomidine for postoperative analgesia in humans without reports of neurological deficit [20]. Maroof et al have used epidural dexmedetomidine at a dose of $1.5 \mu \mathrm{g} / \mathrm{kg}$ to reduce the incidence 
of postoperative chills without reporting neurological deficits [21]. In addition, it has been seen that at two weeks of follow-up the use of dexmedetomidine is not associated with a new onset pain in the back, thighs or legs, or weakness [22]. Most of the knowledge about the use of $\alpha 2$ agonists came from the use of clonidine, where its use has been found to have synergistic effects with local anesthetics [23-26].

In our study we used a dose of $1 \mu \mathrm{g} / \mathrm{kg}$ of dexmedetomidine as an adjunct to analgesia and epidural anesthesia in patients undergoing elective hysterectomy, against a dose of $1 \mu \mathrm{g} / \mathrm{kg}$ of fentanyl. Although we did not find significant differences in the duration of anesthesia, the frequency of requirement of a second dose of anesthesia, it took almost twice the time for patients to reach a maximum motor and sensory level with respect to patients in those that used fentanyl. This contradicts what was previously reported, where an earlier onset of motor and sensory blockade of dexmedetomidine compared with fentanyl in epidural anesthesia has been demonstrated [27-31]. When adjusting the analysis to those patients who maintained single-dose epidural block, we found that patients with dexmedetomidine were lower than patients with fentanyl.

The patient satisfaction rate was high and not different in both patient groups. Although in the fentanyl group, most patients reached a maximum sensory level up to T4, there were no significant differences. In addition, the rate of use of rescue analgesic drugs was very low, in which it was used in a single patient in the dexmedetomidine group. The level of sedation assessed through the Ramsay scale was similar in both groups, with the exception of the evaluations in the 60 and 90 perioperative minutes, where we found a slightly higher level of sedation in patients with dexmedetomidine, similar to the previously reported a greater number of patients with scores $>3$ of maximum Ramsay when using dexmedetomidine [28]. Within the adverse effects of dexmedetomidine, due to respiratory depression, nausea and vomiting [28]. In our patients, the nausea rate was $15.3 \%$ of patients with dexmedetomidine vs. $0 \%$ in patients with fentanyl. It is not known if dexmedetomidine has adjuvant properties in reducing nausea and vomiting, however, the savings in the use of opioids with dexmedetomidine could be associated with the reduction of the risk factor of opioid-induced nausea and vomiting [32-33]. The hemodynamic effects with the use of dexmedetomidine are complex, since when using a loading dose, transient hypertension may occur as a result of direct vasoconstriction, followed by hypotension and bradycardia [34]. The use of dexmedetomidine without the loading dose may decrease hemodynamic instability. In our case, the incidence of hypotension in patients was $76.9 \%$ in the dexmedetomidine group and $88.8 \%$ in patients with fentanyl; On the other hand, the incidence of bradycardia was $46.1 \%$ and $33.3 \%$, respectively. However, we found no significant differences in its intraoperative presentation [35].

Some limitations of our study were that we were unable to evaluate the same recovery in all patients due to the use of a second dose-blocking use, which in a high percentage was due to an indication by schedule, where it was intended to avoid an uncomfortable surgery for the patient.

\section{Conclusion}

Dexmedetomidine is a useful medication for analgesia and anesthesia in patients elective to hysterectomy compared to fentanyl, the safety profile being similar in both anesthetics. In addition, we found that patients with dexmedetomidine took longer to reach their maximum sensory and motor level, so they could slightly prolong the surgeries. During the transoperative period, patients with dexmedetomidine reached a higher level of sedation than patients with fentanyl. We must consider that dexmedetomidine is a more expensive medication than fentanyl, so its use must be personalized, and having fentanyl accessible, it could cover the anesthetic needs of the surgery and the patient. It should also be considered that although the rate of adverse events was similar in both groups, there was a higher incidence in patients in which dexmedetomidine was administered, when using such drugs, they should be alert for the occurrence of adverse events and that The treating doctors can solve the patient's problems, without major complications.

\section{Acknowledgement}

None.

\section{Conflict of Interest}

No conflict of interest.

\section{References}

1. Ebert TJ, Hall JE, Barney JA, Uhrich TD, Colinco MD (2000) The effects of increasing plasma concentrations of dexmetomidine in humans. Anesth Essays Res 93(2): 382-394.

2. J A y F R (2012) Dexmetomidina: Rol actual en anestesia y cuidaddos intensivos. Revista Brasileña de Anestesiologia 62(1): 118-133.

3. Tang C, Xia Z (2017) Dexmetomidine in perioperative acute pain management: a non-opioid adjuvant analgesic. J Pain Res 10: 1899-1904.

4. Yousef AA, Salem HA, Moustafa MZ (2015) Effect of mini-dose epidural dexmetomidine in elective cesarean section using combined spinalepidural anesthesia: a randomized double-blinded controlled study. J Anesth 29(5): 708-714

5. CENETEC (2010) Indicaciones y contraindicaciones de la histerectomía en el segundo nivel de atención. México: Secretariade salud.

6. KG, BR, PG, MJ, SG, DM (2014) Epidural 0.5\% levobupivacaine with dexmetomidine versus fentanyl for vaginal hysterectomy: a prospective study. Indian Journal of Pain 28(3): 149-154.

7. M Matute Crespo, Montero Matamala (2017) Avances farmacológicos en el manejo multimodal de la analgesia perioperatoria. Revista Española de Anestesiología y Reanimación 64(8): 467-471.

8. Lopez SO y Bernal (2010) Dexmetomidina vs fentanyl peridurales en cirugía de abdomen y miembros inferiores. Revista Mexicana de Anestesiología 33(4): 179-186.

9. Lopez SO Bernal (2011) ¿Que adyuvante para sedación: dexmetomidina o fentanyl epidural? Para cirugía abdominal y de miembros imferiores. Revista Mexicana de Anestesiología 34(3): 189-195.

10. JE (1994) Alpha-2 agonist and analgesia. Expert opinion on investigational drugs 1005-1010.

11. S P, H D, Y R, G D (2016) Evaluation of dexmetomidine as an adjuvant to untrathecal bupivacaine in infraumbilical surgeries. J Clin Diagn Res UC13-UC16. 
12. Shah, PJ, RN, CB, KT (2017) Dexmetomidine vs fentanyl with $0.75 \%$ ropivacaine for epidural anesthesia in lower abdominal surgeries - A comparative study. Journal of Anesthesia \& Intensive Care Medicine 3(3).

13. Shaikh SI, Mahesh SB (2016) The Eficacy and Safety of Epidural Dexmetomidine and Clonidine with bupivacaine and clonidine eith bupivacaine in patients undergoing lower limb orthopedic surgeries. J anaesthesiol clin Pharmacol 32(2): 203-209.

14. Belleville JP, Ward DS, Bloor BC, Maze M (1992) Effects of intravenous dexmedetomidine in humans. I. Sedation, ventilation, and metabolic rate. Anesthesiology 77: 1125-1133.

15. US Food and Drug Administration. Precedex label.

16. European Medicines Agency, European Public Assessment.

17. Eisenach JC, De Kock M, Klimscha W (1996) $\alpha 2$-Adrenergic Agonists for Regional Anesthesia: A Clinical Review of Clonidine (19841995) Anesthesiology 85(3): 655-674.

18. Al Ghanem SM, Massad IM, Al-Mustafa MM, Al-Zaben KR, Qudaisat IY, et al. (2009) Effect of Adding Dexmedetomidine versus Fentanyl to Intrathecal Bupivacaine on Spinal Block Characteristics in Gynecological Procedures: A Double-Blind Controlled Study. Am J Appl Sci 6: 882-887.

19. Kalso E, Poyhia R, Rosenberg P (1991) Spinal antinociception by dexmedetomidine, a highly selective $\alpha 2$-adrenergic agonist. Pharmacol Toxicol 68: 140-143.

20. Fukushima K, Nishimi Y, Mori K, Takeda J (1996) Effect of epidurally administered dexmedetomidine on sympathetic activity and postoperative pain in man. Anesth Analg 82: S121.

21. Maroof M, Khan SA, Jain D, Khan RM, Maroof SM (2004) Evaluation of effect of dexmedetomidine in reducing shivering following epidural anesthesia. Anesthesiology 101: A495.

22. Kanazi GE, Aouad MT, Jabbour-Khoury SI, AI Jazzar, Alameddine MM, et al. (2006) Effect of low dose dexmedetomidine or clonidine on the characteristics of bupivacaine spinal block. Acta Anesthesiol Scand 50(2): 222-227.

23. Strebel S, Gurzeler J, Schneider M, Aeschbach A, Kindler C (2004) Smalldose intrathecal clonidine and isobaric bupivacaine for orthopedic surgery: A doseresponse study. Anesth Analg 99(4): 1231-1238.

24. Dobrydnjov l, Axelsson K, Thorn S-E Matthiesen P, Klockhoff $\mathrm{H}$, Holmström B, et al. (2003) Clonidine combined with small-dose bupivacaine during spinal anesthesia for inguinal herniorrhaphy: A randomized double-blinded study. Anesth Analg 96(5): 1496-1503.
25. Dobrydnjovl, Axelsson K, Samarutel J, Holmstrom B (2002) Postoperative pain relief following intrathecal bupivacaine combined with intrathecal or oral clonidine. Acta Anaesthesiol Scand 46(7): 806-814.

26. De Kock M, Gautier P, Fanard L, Hody J, Lavand Home P (2001) Intrathecal ropivacaine and clonidine for ambulatory knee arthroscopy. Anesthesiology 94(4): 574- 578.

27. Kalso EA, Poyhia R, Rosenberg PH (1991) Spinal antinociception by dexmedetomidine, a highly selective $\alpha 2$-adrenergic agonist. Pharmacol Toxicol 68(2): 140-143.

28. Gupta K, Rastogi B, Gupta PK, Jain M, Gupta S, et al. (2014) Epidural 0.5\% levobupivacaine with dexmedetomidine versus fentanyl for vaginal hysterectomy: a prospective study. Indian Journal of Pain 28(3): 149154.

29. Hanoura SE, Hassanin R, Singh R (2013) Intraoperative condition and quality of postoperative analgesia after adding dexmedetomidine to epidural bupivacaine and fentanyl in elective cesarean section using combined spinal-epidural anesthesia. Anesth Essays Res 7(2): 168-172.

30. Kim SY, Chang CH, Lee JS, Kim YJ, Kim MD, et al. (2013) Comparison of the efficacy of dexmedetomidine plus fentanyl patient-controlled analgesia for pain control in uterine artery embolization for symptomatic fibroid tumors or adenomyosis: a prospective, randomized study. J Vasc Interv Radiol 24(6): 779-785.

31. Abdelmageed WM, Elquesny KM, Shabana RI, Abushama HM, Nassar AM (2011) Analgesic properties of a dexmedetomidine infusion after uvulopalatopharyngoplasty in patients with obstructive sleep apnea. Saudi J Anaesth 5(2): 150-156.

32. Lin TF1, Yeh YC, Lin FS, Wang YP, Lin CJ, et al. (2009) Effect of combining dexmedetomidine and morphine for intravenous patient-controlled analgesia. Br J Anaesth 102(1):117-122.

33. Roberts GW, Bekker TB, Carlsen HH, Moffatt CH, Slattery PJ, et al. (2005) Postoperative nausea and vomiting are strongly influenced by postoperative opioid use in a dose-related manner. Anesth Analg 101(5): 1343-1348.

34. Marret E, Kurdi O, Zufferey P, Bonnet F (2005) Effects of nonsteroidal antiinflammatory drugs on patient-controlled analgesia morphine side effects: meta-analysis of randomized controlled trials. Anesthesiology 102(6): 1249-1260.

35. Khan AL, Singh RB, Tripathi RK, Choubey S (2015) A comparative study between intrathecal dexmedetomidine and fentanyl as adjuvant to intrathecal bupivacaine in lower abdominal surgeries: a randomized trial. Anesth Essays Res 9(2): 139-148. 